\title{
Setting education on the global agenda: A historical perspective
}

\author{
P. T. M. Marope
}

Published online: 26 February 2015

(C) UNESCO IBE 2015

I am pleased to introduce this special issue, which builds on and further strengthens the already solid partnership between UNESCO International Bureau of Education (IBE) and the University of Geneva.

This is indeed a special issue, as it uses a historical perspective to tackle three important aspects of education policies that are often addressed in articles published in Prospects and elsewhere, but are rarely featured in an explicit and systematic way. These aspects are: the circulation of knowledge and the genesis of education policies; the mediators of dissemination (individuals and social groups); and the materials and channels to enable the "transit of knowledge" (Secord 2004, p. 670).

Focusing on the ways in which educational knowledge was produced and distributed during the 20th century, the issue also synthesizes recent contributions in this area, especially as they relate to the development of transnational history approaches in education. Transnational history takes as its starting point "the interconnectedness of human history as a whole, and, while it acknowledges the extraordinary importance of states, empires, and the like, it pays attention to networks, processes, beliefs, and institutions that transcend these politically defined spaces" (Sven Beckert, in Bayly et al. 2006). In particular, transnational approaches to the history of education are concerned with questions of the transfer, reception, negotiation and appropriation of given ideas and texts, but also institutions, as they cross national, cultural and linguistic boundaries. Work of this kind, which understands educational phenomena as a dynamic space for dissemination and exchange, seeks to go beyond a focus on their study in their isolated initial contexts (Macdonald 2013, p. 21).

Since the 20th century was characterized by the "institutionalization of the international" in education, through new international organizations and associations, the authors in this issue pay particular attention to UNESCO and the IBE, as well as the League of

P. T. M. Marope $(\varangle)$

UNESCO International Bureau of Education, C.P. 199, 1211 Geneva 20, Switzerland

e-mail: ibe.prospects@unesco.org 
Nations, the International Labour Office, and the International League for New Education. These examples also demonstrate the preponderant role that Geneva played, and continues to play, as a platform for such dissemination, a role the authors bring to light by setting it in its international context. Have mechanisms of circulation had an impact? Are they measurable? Can they be understood and made objective, and, if so, what methods are most appropriate? Can their impact be reduced to a logic of export-import, or does it operate through more complex trajectories? In particular, how can we interpret and understand the phenomena in which the models being transmitted are hybridized, in light of recently formulated concepts that describe their effects, such as the concept of glocalization?

These are not easy questions to answer, even for a culture one knows from the inside. And the difficulties only multiply when one confronts both personal and official accounts from another time, as reflected in a wealth of unpublished documents, deposited in various archives, including those of the IBE and the Jean-Jacques Rousseau Institute. Scholarly distinction is a given in such work, but the ideal editors and authors would also need to be able to communicate with an audience beyond their research field, and to make this topic relevant to a wider readership. This was a challenge that Rita Hofstetter and Joëlle Droux, the guest editors of this special issue, set themselves from the beginning. Professor at the University of Geneva and director of the Jean-Jacques Rousseau Institute's archives, Rita Hofstetter is a historian of education, whose research focuses, among other topics, on the history of the IBE. She and Joëlle Droux, also a historian of education, co-lead the Social History of Education Research Group (ERHISE) at the University of Geneva. This issue has its origins in the work of the ERHISE team, in combination with the Laboratoire des Archives of the Jean-Jacques Rousseau Institute (Faculty of Psychology and Education, University of Geneva).

Varied though they are, the articles in this issue clearly show the three common threads mentioned above. Authors concerned with the first theme, the circulation of knowledge and the genesis of educational policies, focus on the temporal aspect of dissemination mechanisms. They identify periods that were particularly conducive to the circulation and exchange of knowledge or, conversely, contexts that were less favourable (e.g., wars, economic crises). Between these two poles, they point to phases during which the objectives, ideas and models originating abroad were assimilated into national education systems. They also identify and analyse the links between education policies and the propagation of new knowledge.

In introducing the second theme-mediators of dissemination, the authors aim to develop a cartography of the diverse range of actors involved in these dynamic transnational processes. They focus on formal and informal networks, such as occupational associations, academic circles, networks of experts, trade union federations, and churches, as well as key international organizations. An approach that combines biography and prosopography (the study of groups within their historical context) is particularly relevant here, as it brings into sharper focus the individual trajectories of those who disseminated models. In time, as studies accumulate, they may help us to better understand the collective logic underlying the ways in which these transnational transfers took root in different cultural settings.

The third theme focuses on the specific channels which made it materially and technically possible to circulate ideas between a wide range of education systems and institutional and individual actors. Among the topics the authors analyse are the configuration of spaces conducive to transfers (congresses and their transformation over the $19^{\text {th }}$ and $20^{\text {th }}$ centuries) and institutional networks (schools emerging from a specific model of teaching), as well as publications (specialized journals) that made dissemination possible to varying 
degrees. But it was also through legal instruments that these transfers were organized, and some of the authors shed light on the legal roles played by international conventions.

The importance of this atypical special issue of Prospects stems from its deep historical perspective, which can enable us to re-evaluate our goals and to re-think and properly appreciate the merits - or realize the limitations - of some of our guiding principles. Investigating the history of ideas which have shaped education over the past century or so is a worthwhile effort in itself. Using transnational lenses is particularly fruitful, as this field of research has the potential to "develop new connections and insights both within and between...various scholarly traditions" (Saunier 2004, p. 111, cited in Macdonald 2013, p. 9). It is in this vein that C.A. Bayly (in Bayly et al. 2006, pp. 1452; 1461) highlights the need to study "the lived experience of those ideas" and to escape from the notion that they were "simply disseminated". It emphasizes how new contexts change the way in which educational ideas are deployed and assumed.

In addition, getting to the "genetic code" of current trends in the field of education by understanding foundational documents (e.g., the UN Declaration of the Rights of the Child) and various shifts in education policy is bound to crystalize ideas that we may try to put into practice today, perhaps without always pausing to ponder their complex and revealing lineage. Although this stimulating collection of articles does not intend to answer such questions, it helps us begin to ask them.

\section{References}

Bayly, C. A., Beckert, S., Connelly, M., Hofmeyr, I., Kozol, W., \& Seed, S. (2006). AHR conversation: On transnational history. American Historical Review, 111(5), 1440-1464.

Macdonald, S. (2013). Transnational history: A review of past and present scholarship. London: Centre for Transnational History, University College London. http://www.ucl.ac.uk/cth/objectives/simon_ macdonald_tns_review

Saunier, P.-Y. (2004). Circulations, connexions et espaces transnationaux [Circulation, connections and transnational spaces]. Genèses, 57, 110-126.

Secord, J. A. (2004). Knowledge in transit. Isis, 95(4), 654-672. 